\title{
Sexual adjustment after spinal cord injury (SCI) focusing on partner experiences
}

\author{
M Kreuter RPT, ${ }^{1}$ M Sullivan PhD, ${ }^{2}$ A Siösteen RPT PhD ${ }^{1}$ \\ ${ }^{1}$ Spinal Injuries Unit and ${ }^{2}$ Health Care Research Unit, Sahlgrenska University Hospital, \\ S-413 45 Gothenburg, Sweden.
}

In addition to the physical disability, a spinal cord injury affects self esteem and partner relationships. This study addressed partner experiences in relation to sexual interest, behaviour and satisfaction. A measure of satisfaction within relationships was also included. Forty-nine partners of SCI persons completed a comprehensive survey including an 80 item questionnaire and a VAS quality-oflife measure. Partner ages ranged from 18 to 79 years (median 34 years). Thirty-nine partners were women and 10 partners were men. Significance testing of relationships included bivariate, partial and multiple correlation procedures. Sixty-one per cent of the partners appreciated the quality of their sexual relationship and most partners $(84 \%)$ considered their relationship overall to be satisfying. Half of the couples engaged in sex, with or without intercourse, once a week or more. Fifty-five per cent of the partners reported being content with the frequency of their sexual interaction while one third would have wished more frequent activity. Almost half of the partners $(45 \%)$ considered their current sex life to be as good as or even better than their previous sex life. High general satisfaction with life, a varied repertoire of rewarding sexual expressions, including intercourse and concern about the able bodied partner's sexual pleasure were positive predictors of an active and fulfilling sexual relationship. From the partner's perspective, feelings of emotional closeness, mutual concerns and willingness to engage in a variety of sexual activities seem to be more important for sexual fulfilment than the physiological aspects of sexuality.

Keywords: spinal cord injuries; sexual adjustment; sexual partner relationships; marriage.

\section{Introduction}

The consequences of a spinal cord injury (SCI) will not only include the physical aspects of sexuality but also the self esteem of the injured person and the quality of any intimate relationships.

The extent and severity of a SCI directly influence the degree to which physical changes relevant to sexual response occur. Although the disability may have profound effects on sexual expression as measured by normative standards, it is apparent that persons with SCI do not lose their need for sexual intimacy. ${ }^{1,2,3,4}$ The sexual expression of persons with SCI may be affected not only by their particular physical condition but also by the attitudes of society and of their partners toward the disability. Further- more, the impact of SCI on a person's sexuality will be closely related to the SCI person's view of himself, body image and self esteem, and will be highly influenced by his or her confidence in interpersonal relationships. ${ }^{1}$

In the present study sexuality is viewed as a dynamic learning process with psychological, social and behavioural components which interact with each other. ${ }^{5}$ The psychological component includes sexual interest and satisfaction as well as the person's perceived quality of life, self esteem and feelings of interpersonal attractiveness. The social component characterises the nature of the couple's relationship and the behavioural component comprises the repertoire of sexual expressions they use. 
Several studies have shown that SCI has a short term impact on marriage indicated by a rise in divorce rates. ${ }^{6-9}$ However, marriages that do survive are generally viewed as satisfying, ${ }^{10}$ and it has been shown that SCI persons often have a positive and satisfying marital relationship. ${ }^{11-13}$

Urey \& Henggeler ${ }^{14}$ found that SCI husbands were less sensitive to their wives' preferences in sexual activity and received less pleasure from sexual activity than did able bodied husbands. They also confirmed that both husbands and wives in distressed SCI marriages engaged in fewer activities both alone and as a couple. Furthermore, they postulated that the degree of sexual satisfaction or dissatisfaction might be less important for a couple with an SCI partner. ${ }^{15}$

A study of 16 Israeli couples in which the husbands had sustained a SCI showed that an inability to become pregnant was the major source of dissatisfaction for the wives, whereas the sexual relationship was of less importance to them. ${ }^{16}$

In another study of 25 wives of SCI men, marital satisfaction was reasonably high, although the frequency of sexual activity reported was low. The majority of spouses in this study reported that their partner's injury had resulted in some positive changes such as increased communication and intimacy. ${ }^{17}$

Most of the literature concerning the various aspects of sexuality after SCI focuses on the injured person. As sexual interaction is a joint responsibility, however, the impact of disability is more adequately assessed by asking both partners. Several researchers have requested research addressing sexual problems and adjustment issues from the partner's point of view. . $^{18-21}$ Unfortunately, little has been published to document partner sexual concerns in relationships that include a SCI person.

A better knowledge of sexual adjustment following spinal cord injury from the perspective of the SCI person's partner would improve information and the calibre of sexual counselling currently available to SCI persons and their partners.

The purpose of this study was to explore how partners of a sample of SCI persons experience the sexual and emotional aspects of their intimate relationships. Two main questions were addressed in this research:

1 How do partners of SCI persons experience the sexual and emotional aspects of their intimate relationships?

2 What are the main psychosocial behavioural, physical and sociodemographic predictors of sexual adjustment from the partner's perspective?

\section{Method and study population}

\section{Sample and procedure}

In order to identify partners of persons with SCI a consecutive series of 252 persons with traumatic spinal cord injury were contacted. The injured persons had been admitted to the Gothenburg Spinal Injuries Unit between November 1982 and July 1991.

Eighty-five SCI persons were excluded for the following reasons: death (36), recovery from injury (Frankel class E) (37), inability to locate (5), juvenile status (4), language difficulties (2) and psychiatric illness (1).

Of the remaining $167 \mathrm{SCI}$ persons, 63 were living in stable partnerships and their partners formed the basis of the research sample.

Initial contact was made by telephone with an explanation of study aims. Basic sociodemographic data were also collected at this time, as well as data from the SCI persons to determine whether their physical and psychosocial functioning was related to their partners' sexual adjustment.

Questionnaires with letters further describing the rationale for the study were retrogradely mailed to the couples who were asked to complete the questionnaires separately. Prospective subjects were assured that their completed responses would be identified only by code numbers and that all information would remain confidential. To encourage participation, up to two follow up mailings were used.

Forty-nine couples (78\%) completed and returned the questionnaires. Some who chose not to participate did so because they found the questions 'too personal'.

The participating partners' ages ranged 
from 18 to 79 years (median 34 years). Twenty-nine partners were women and ten partners were men. The couples had been married or cohabiting from between one to 51 years (median 6 years). All couples were living in their own homes.

No significant demographic differences were found between the study participants and nonparticipants. The basic characteristics of the two groups are shown in Table I. Table II indicates that many SCI respondents reported changes in sexual function following injury. None of the SCI persons was using an indwelling catheter.

\section{Measurement instruments}

\section{Relationship questionnaire}

The questionnaire, comprising 80 items, was created specifically for this study and was designed to measure several dimensions of sexuality (sexual function, interest, behaviour and satisfaction) as well as the emotional quality of the relationship (feelings of

Table I Characteristics of the SCI subjects

\begin{tabular}{|c|c|c|c|}
\hline & $\begin{array}{l}\text { Respondents } \\
\quad(n=49)\end{array}$ & $\begin{array}{l}\text { Nonrespondents } \\
\quad(n=14)\end{array}$ & $p$ value \\
\hline Age at injury & & & NS \\
\hline Median & $30.5 \mathrm{yrs}$ & 29.5 yrs & \\
\hline SD & 15.6 & 15.0 & \\
\hline Range & $14-69$ yrs & $20-66$ yrs & \\
\hline Time since injury & & & NS \\
\hline Median & $5.5 \mathrm{yrs}$ & $5.0 \mathrm{yrs}$ & \\
\hline SD & 2.8 & 2.4 & \\
\hline Range & $1-9$ yrs & $1-9$ yrs & \\
\hline Injury level & $\mathrm{C} 1-\mathrm{L} 4$ & C3-L4 & \\
\hline Tetraplegia, complete (Frankel A, B, C) & $18(37 \%)$ & $1(7 \%)$ & NS \\
\hline Tetraplegia, incomplete (Frankel D) & $7(14 \%)$ & $4(29 \%)$ & NS \\
\hline Paraplegia, complete (Frankel A, B, C) & $14(29 \%)$ & $4(29 \%)$ & NS \\
\hline Paraplegia, incomplete (Frankel D) & $10(20 \%)$ & $5(36 \%)$ & NS \\
\hline
\end{tabular}

NS = not significant, Fisher's permutation test

Table II Sexual functioning after injury ( $n=49$ SCI subjects)

\begin{tabular}{lcccc}
\hline & $\begin{array}{c}\text { Unaltered } \\
\%\end{array}$ & $\begin{array}{c}\text { Decreased } \\
\text { to some } \\
\text { extent } \%\end{array}$ & $\begin{array}{c}\text { Much } \\
\text { decreased } \\
\%\end{array}$ & $\begin{array}{c}\text { Absent } \\
\%\end{array}$ \\
\hline $\begin{array}{l}\text { Erection sufficient for intercourse } \\
(n=39)\end{array}$ & 5 & 33 & 31 & 31 \\
$\begin{array}{l}\text { Vaginal lubrication } \\
\quad(n=10)\end{array}$ & 20 & 20 & 20 & 40 \\
$\begin{array}{l}\text { Genital sensibility } \\
\text { Males }(n=39)\end{array}$ & 3 & 26 & 28 & 43 \\
Females $(n=10)$ & 0 & 30 & 60 & 10 \\
\hline & Almost & Often & Rarely & Never \\
& always \% & $\%$ & $\%$ & $\%$ \\
\hline Experiences of orgasm & & & & 47 \\
$\quad$ Males $(n=34)$ & 23 & 15 & 15 & 60 \\
\hline Females $(n=10)$ & 10 & 10 & 20 & 47 \\
\hline
\end{tabular}


affection and intimacy, ability to solve problems within the relationship, ability to communicate about sex with the partner and satisfaction with these areas and the relationship as a whole). Additional data were included to determine perceived sexual attractiveness and concerns about partner sexual satisfaction.

Six items from the questionnaire, covering sexual interest, activity and satisfaction, were pooled to form a composite variable, the Sexual Interest, Activity and Satisfaction (SIAS) scale (Table III). This variable meets the basic criteria for a multi-item scale, i.e. a reliability estimate exceeding 0.70 and principal component loadings beyond 0.40 . Internal consistency determined by Cronbach's alpha ${ }^{22}$ was 0.86 and a principal components analysis (Nunnally, 1978) $)^{23}$ confirmed the unidimensionality of the scale. Factor loadings on the principal component which accounted for $62 \%$ of the variance ranged between 0.61 and 0.88 . Scores on the SIAS scale ranged from $6-28$ (mean 17.6 \pm 7.0 ; median value 19 ). The SIAS scale was subsequently used as the dependent variable.

Seven items covering sexual expressions used by the couple formed a second com- posite variable, The Sexual Behaviour scale, and seven items relating to emotional intimacy, affection and communication were combined to form a third composite variable, the Emotional Quality of the Relationship scale. Standard methodology to ensure construct validation of these two scales included calculation of Cronbach's alpha (0.96 and 0.85 respectively) and principal components analyses. The range of scores on the Sexual Behaviour scale was 7-49 (mean $30.7 \pm 13.5$; median value 32.5 ), and that for the Emotional Quality of the Relationship scale was 7-28 (mean $22.5 \pm$ 4.8; median value 24).

\section{Quality-of-life recording}

Both SCI persons and their partners recorded their perceptions of overall quality of life (QL) on a $0-100$ visual analogue scale (VAS). Endpoints were labelled $0=$ 'very low' and $100=$ 'very high'. The median value of partner QL ratings was 71.5 (ranging from 4 to 100 ; mean $63.2 \pm 31.5$ ). For SCI persons the median QL rating was 70.5 (ranging from 5 to 100 ; mean $64.4 \pm 25.1)$.

To further explore QL from the perspect-

Table III The Sexual Interest, Activity and Satisfaction (SIAS) scale

\begin{tabular}{|c|c|c|c|}
\hline \multicolumn{4}{|c|}{ Areas and underlying questions } \\
\hline Area & Questions & Scale point & Score \\
\hline Sexual desire & Is your sexual desire lowered? & From never to very often & $4-1$ \\
\hline Sexual activity & $\begin{array}{l}\text { How often do you and your partner } \\
\text { engage in sexual activity, with or } \\
\text { without intercourse? }\end{array}$ & $\begin{array}{l}\text { From every other day to } \\
\text { never }\end{array}$ & $8-1$ \\
\hline $\begin{array}{l}\text { Sexual } \\
\quad \text { satisfaction }\end{array}$ & $\begin{array}{l}\text { Do you generally enjoy the sexual } \\
\text { part of your relationship? }\end{array}$ & $\begin{array}{l}\text { From very much to not } \\
\text { at all }\end{array}$ & $4-1$ \\
\hline $\begin{array}{l}\text { Sexual } \\
\quad \text { satisfaction }\end{array}$ & $\begin{array}{l}\text { Do you believe that your partner } \\
\text { generally enjoys the sexual part of } \\
\text { your relationship? }\end{array}$ & $\begin{array}{l}\text { From very much to not } \\
\text { at all }\end{array}$ & $4-1$ \\
\hline $\begin{array}{l}\text { Sexual } \\
\text { satisfaction }\end{array}$ & $\begin{array}{l}\text { How often would you like to have } \\
\text { sex with your partner? }\end{array}$ & $\begin{array}{l}\text { More often than now } \\
\text { Same as now } \\
\text { Less often than now }\end{array}$ & $3-1$ \\
\hline \multirow[t]{2}{*}{$\begin{array}{l}\text { Sexual } \\
\text { satisfaction }\end{array}$} & $\begin{array}{l}\text { How does your current sex life } \\
\text { compare your sex life before your } \\
\text { injury/your partner's injury? }\end{array}$ & $\begin{array}{l}\text { From much better to } \\
\text { much worse }\end{array}$ & $5-1$ \\
\hline & Composite of question & Summary of scale points & $28-6$ \\
\hline
\end{tabular}


ive of SCI persons, a brief function and mood self-assessment questionnaire, containing 22 items derived by Lundqvist et al from an extensive battery of questionnaires, ${ }^{24}$ was administered. This questionnaire contains ten items from the Sickness Impact Profile (SIP) ${ }^{25}$ covering functional limitations in mobility, body care, movement and social interaction, six items from the Hospital Anxiety and Depression (HAD) scale $^{26}$ measuring depressive feelings and six items from The SCI Problem scale defining the SCI person's perception of loss of independence. The procedure and metric properties of this quality-of-life measure have been described elsewhere. ${ }^{24}$

\section{Statistical methods}

All data were analysed by means of the Statistical Analysis System (SAS). ${ }^{27}$ Standard methodology was applied for construct validation of scaling procedures including the calculation of Cronbach's alpha and principal components analyses. ${ }^{22,23}$ Fisher's nonparametric permutation test ${ }^{28}$ was used for significance testing of differences between groups, sexes and the level and completeness of injury. The 0.5 per cent significance level was chosen. Relationships between the dependent variable, SIAS scale, and a number of independent variables, including sociodemographic data, neurological and functional status, overall QL and psychosocial and behavioural data were explored by means of Pitman's nonparametric permutation test. ${ }^{28}$ A step-bystep model including bivariate, ${ }^{28}$ partial $^{29}$ and multiple correlation procedures was applied for prediction of SIAS scale scores from a selection of potentially influential variables.

\section{Results}

\section{Emotional quality of the relationship}

The majority of partners $(84 \%)$ considered their relationships overall to be satisfactory and all but one respondent felt substantial affection for their partner (Fig 1). Most of the respondents $(78 \%)$ indicated that they frequently expressed this affection verbally and nonverbally. Eighty-four per cent of the partners reported being satisfied with the manner in which the SCI person demonstrated affection to them. Forty-two partners $(86 \%)$ were also satisfied with the manner in which relationship problems were solved by the couple (Fig 1). Only six partners had considered divorce or separation. Sixtyseven per cent of the partners thought they were able to have open and honest communication about sex within the relationship and $33 \%$ thought that sex was a difficult subject to discuss (Fig 1).

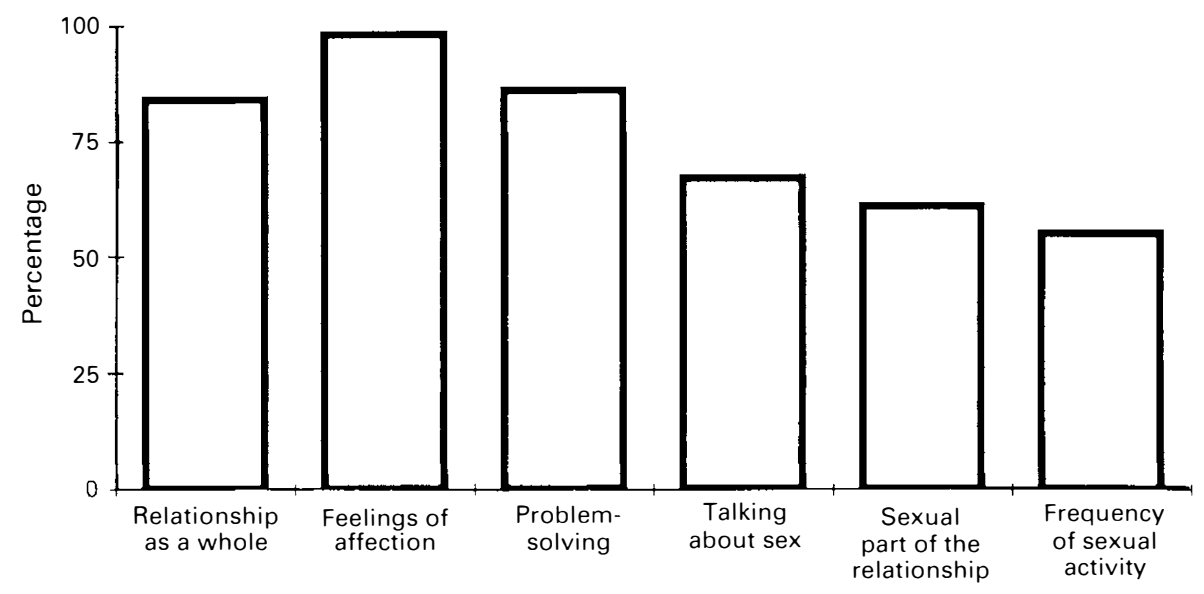

Figure 1 Partner satisfaction with different areas of the intimate relationship ( $n=49$ partners of SCI persons). 


\section{Sexual interest and satisfaction}

Twenty-two per cent of the respondents, two men and nine women, reported having frequent low sexual desire. Most (94\%) considered sex an important part of their lives. However, five men and thirteen women $(37 \%)$ thought that their interest in sex had decreased because of the partner's spinal cord injury. Two female partners reported increased sexual interest.

One man and nineteen women (41\%) considered the injured partner to be the one with the greater sexual interest in the relationship, and $18 \%$ of the respondents (four men and five women) considered themselves to have more interest in sex than their injured partner.

Sixty-one per cent of the partners (five men and 25 women) appreciated their current sex life (Fig 1) and slightly more (65\%) thought that their injured partner enjoyed the sexual part of the relationship.

Nearly half $(45 \%)$ of the partners considered their current sex life to be as good as (three men and eight women) or better (one man and 10 women) than their previous sex life, stating that their sexual relationship was now more equal and gave them more sexual satisfaction.

Emotional factors such as honesty, trust, closeness, mutual respect, communication, caring and appreciation were reported to be important in maintaining a positive and satisfying sexual relationship, as were the use of sensuality and sexual fantasy. The injured person's inability to achieve orgasm was perceived as interfering negatively with the sexual satisfaction of some of the partners.

\section{Sexual activity and behaviour}

Half of the respondents $(49 \%)$ reported sexual interaction, with or without intercourse, once a week or more. Five partners claimed that their sexual activity had ceased completely, and a further four partners indicated that sexual contact occurred less than once a year

Approximately half of the partners (five men and 22 women) reported being content with the frequency of sexual activity (Fig 1). However, more than one third of the partners (four men and 15 women) expressed a wish to engage in sexual activities more often. Two female partners would have preferred less sexual interaction.

Slightly more than half of the partners (55\%, 5 men and 22 women) reported that sexual activity was mostly initiated by their injured partner, whereas 14 partners $(29 \%$, three men and 11 women) reported that the sexual initiative was mutual.

Four men and eighteen women (45\%) reported a decline in the frequency of sexual activity. The most commonly reported reasons for the decline were the SCI person's physical limitations and decreased sexual ability, or the partner's unwillingness to engage in sex. In addition, the SCI person's decreased sexual desire and interest in sex contributed to diminished sexual activity. On the other hand, several partners reported that the injury had caused some positive changes in their sex life such as increased playfulness, prolonged foreplay and feelings of sexual equality.

Of the 44 couples who were sexually active, $66 \%$ of the partners and $34 \%$ of the injured persons experienced orgasm on most occasions during sexual activity (Table II). Four partners $(9 \%)$ reported engaging in intercourse every time they had sexual contact, and another 13 partners (29\%) reported frequent intercourse. Twenty-six partners $(59 \%)$ indicated that they seldom or never had intercourse. Manual and oral simulation of secondary erogenous zones such as the ears, lips, neck and the sensitive area around the level of injury were an important and pleasurable part of the sexual repertoire of many couples, as reported by the partners (Figure 2).

A quarter $(24 \%)$ of the partners reported that they experimented with different sexual expressions more often since their partner's injury or with non-SCI partners. Seven couples used technical aids to increase sexual pleasure, and five injured men used vasodilatory injections to achieve an erection sufficient for coitus.

No significant gender differences were found concerning the various sexual and emotional aspects of the relationships. However, the number of men included in this study was small. 


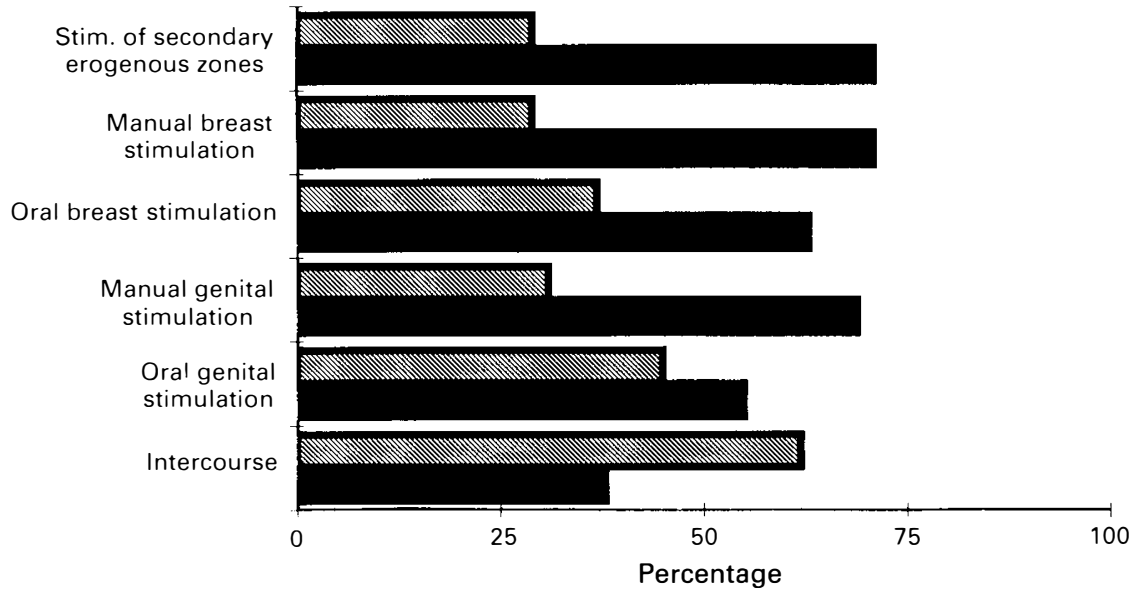

Figure 2 Relative frequency of use of various sexual expressions $(n=49)$.

Sexual adjustment in relation to psychosocial, behavioural, physical and sociodemographic variables

As can be seen from Table IV, partner sexual adjustment as measured by the SIAS scale, was significantly correlated to high partner perceived overall quality of life $(p<0.001)$ as well as the SCI person's physical and psychosocial well being (SIP $p<0.01$, HAD $p<0.001)$ and perception of high quality of life $(p<0.05)$.

The emotional quality of the relationship and mutual concerns about the sexual pleasure of the partner were positively correlated to active and satisfying sexual fulfilment $(p<0.001$ and $p<0.001$ respectively).

An extended and varied repertoire of sexual behaviours and willingness to experiment with a variety of different sexual expressions were significantly correlated to higher SIAS scores $(p<0.001$ and $p<$ 0.001 respectively). Furthermore, the ability to maintain erections and to engage in intercourse was positively correlated to sexual satisfaction $(p<0.05$ and $p<0.001$ respectively), as was the frequency of experienced orgasm $(p<0.001)$.

Youth $(p<0.001)$ and injury at young age $(p<0.001)$ were significantly correlated to high scores on the SIAS scale. The level and completeness of the SCI person's lesion showed no significant correlation with the partner's sexuality, although there was a significant correlation between the injured person's preserved genital sensibility and the partner's perceived sexuality $(p<0.001)$.

Partial and multiple correlations were used to determine which of the measured variables were the best independent predictors of the sexual interest, activity and satisfaction of partners, as defined by the SIAS scale. Sixty-two per cent of the variance was explained by four variables: the partner's perception of overall quality of life (the higher the QL the better), the repertoire of sexual behaviours used (the greater the variety of sexual acts the better), the extent of concern shown by the SCI person towards the partner's sexual pleasure (the greater the concern the better) and the degree of genital sensation preserved in the SCI person (the more preserved sensation the better).

\section{Discussion}

In this study the majority of partners considered their relationship with an SCI partner to be satisfying overall, with considerable mutual affection. These findings are commensurate with studies of unbroken marriages among able bodied couples (30) 
Table IV Sexuality in relation to psychosocial, behavioural, physical and sociodemographic variables ( $n=49$ partners of SCI persons)

\begin{tabular}{|c|c|c|}
\hline Characteristics of variables & $r$ & $p$ value \\
\hline \multicolumn{3}{|l|}{ Psychosocial variables } \\
\hline The Emotional Quality of the Relationship scale & 0.55 & 0.001 \\
\hline The partner's total QL rating & $0.71^{\mathrm{a}}$ & 0.001 \\
\hline The partner's concerns about the SCI person's sexual pleasure & 0.79 & 0.001 \\
\hline The partner's feelings of being sexually attractive & 0.22 & NS \\
\hline The partner's altered sexual interest & 0.45 & 0.01 \\
\hline Partner being caretaker for the SCI person & -0.33 & 0.05 \\
\hline The SCI person's total QL rating & 0.35 & 0.05 \\
\hline The SCI person's mental state (HAD) & -0.47 & 0.001 \\
\hline The SCI person's physical and social function (SIP) & -0.43 & 0.01 \\
\hline The SCI person's perceived loss of independence (SCI Problem scale) & 0.11 & NS \\
\hline The SCI person's concerns about the partner's sexual pleasure & $0.76^{\mathrm{a}}$ & 0.001 \\
\hline The SCI person's feelings of being sexually attractive & 0.46 & 0.01 \\
\hline \multicolumn{3}{|l|}{ Behavioural variables } \\
\hline The Sexual Behaviour scale & $0.82^{\mathrm{a}}$ & 0.001 \\
\hline Experimentation with different sexual expressions & 0.56 & 0.001 \\
\hline The frequency of having intercourse & 0.64 & 0.001 \\
\hline \multicolumn{3}{|l|}{ Physical variables } \\
\hline The partner's experiences of orgasm & 0.58 & 0.001 \\
\hline The SCI person's experiences of orgasm & 0.39 & 0.05 \\
\hline The SCI person's level of lesion & 0.01 & NS \\
\hline The SCI person's completeness of lesion & -0.31 & NS \\
\hline The SCI person's genital sensibility & $0.49^{\mathrm{a}}$ & 0.001 \\
\hline The SCI person's ability to achieve erection & 0.42 & 0.01 \\
\hline \multicolumn{3}{|l|}{ Sociodemographic variables } \\
\hline The partner's age & -0.55 & 0.001 \\
\hline The partner's level of education & 0.30 & NS \\
\hline The partner's employment & 0.29 & NS \\
\hline The SCI person's age & -0.61 & 0.001 \\
\hline The SCI person's age at injury & -0.64 & 0.001 \\
\hline Time since injury & -0.12 & NS \\
\hline The SCI person's level of education & 0.38 & 0.05 \\
\hline The SCI person's employment & 0.09 & NS \\
\hline
\end{tabular}

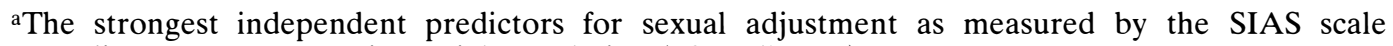
according to nonparametric partial correlation (Mantel's test).

$r=$ Pearson's correlation coefficient.

$p=$ Pitman's permutations test.

NS $=$ not significant

which indicate that the marriages are experienced as satisfying.

Respondents reported that there were acts of physical and verbal intimacy and expressed affection pleasing to both individuals. The manner in which these feelings were expressed included words, touching, caressing gestures, tenderness and consideration. Mutual endearments have been shown to be key ingredients to a satisfying marital and sexual relationship. ${ }^{31}$ If respect, caring and enjoyment are lacking, sexual satisfaction will decline in most close relationships.

Many of the partners stated that they could easily talk about sexual matters with their injured partner. Other studies ${ }^{30,32-35}$ have demonstrated that open and honest communication is essential to a satisfying sexual relationship. In close relationships, 
both partners have the responsibility to communicate their views as honestly and accurately as possible. Open communication tends to dispel misconceptions which may be even more important in relationships where one of the partners has a physical disability.

Only $9 \%$ of the couples in this study who were sexually active reported having sexual intercourse every time they initiated sexual contact. Approximately half of the couples were using orogenital sex or manual stimulation as their most frequent form of sexual activity. Since the majority of partners experienced orgasm most of the times during sexual interaction and expressed satisfaction with their current sex life, it is clear that coitus is not always the most important source of sexual satisfaction. Thus, sexuality should be considered in its full sense and not confined to sexual intercourse. Studies investigating the female sexual response have shown that manual and oral sexual stimulation are effective ways for women to experience orgasm. ${ }^{36,37}$

Low sexual desire was reported by less than a quarter of the partners studied and nearly all considered sex important. However, fewer of the partners were satisfied with the sexual part of their relationship and the frequency of their sexual activities. Current sexual fulfilment was reduced for nearly one third of the partners. Absent or decreased sexual activity might be due to the stressful situation and emotional reactions engendered by a spinal cord injury rather than the physical consequences of the injury itself. This is supported by the finding that perceived low overall QL was closely correlated to negative sexual adjustment. The SCI person's lowered self esteem, performance anxiety and negative body image might also explain the diminished sexual activity.

The partner's perceived high quality of life was an important predictor of positive sexual adjustment. Having an active and fulfilling sex life has a positive effect on many aspects of living and improves quality of life. On the other hand, a high quality of life will also have a positive influence on an individual's sex life. In an earlier study the present researchers found that the quality of life, perceived by the SCI person through a global rating, was closely related to sexual adjustment. ${ }^{35}$

Further predictors of a satisfying sexual adjustment were the injured person's concerns about the sexual pleasure and enjoyment of their partner, and a varied repertoire of sexual behaviours. As sexuality extends beyond the person's physiological capacity for intercourse and covers an expanded sexual repertoire, a focusing on sensuality rather than on achievement may lead to positive developments in a couple's relationship and increased feelings of sexual equality for both partners. This might explain why some partners considered their current sexual relationship with an SCI person to be better than one with a noninjured partner. Studies of áble bodied couples have shown that partners in equitable relationships are more content in the relationship and more willing to experiment sexually. ${ }^{38,39}$ It is hypothesised that the high level of participation in the information and counselling at the Gothenburg SIU may have contributed to positive sexual attitudes and an interest in experimenting with various sexual options.

Partner sexual satisfaction was not correlated with the SCI person's level or completeness of lesion, a finding also consistent with other studies. ${ }^{2,35}$ However, the preservation of genital sensation was shown to be an important factor. Given that the genital area is a primary focus of sexual excitement, it is understandable that preserved genital sensation in the SCI person is important to enhance mutual sexual pleasure.

While this study is unique in that it focused on the impact of a spinal cord injury on the sexual and emotional aspects of intimate relationships, from the perspective of the injured person's partner, it has some obvious limitations. The study lacks a control group of able bodied couples and relies on volunteer couples. The risk of bias due to social desirability factors must also be acknowledged since the study addressed psychosocial and sexual issues. However, the heterogeneity of the study group was satisfying and the variation of responses allowed a series of analyses to better describe possible predictors of sexual adjust- 
ment. Forthcoming studies will address the personality characteristics of partners in preinjury and postinjury relationships and a qualitative study will be undertaken to better understand the complexity of sexuality and partner relationships following spinal cord injury.

\section{Conclusion}

The results of this study show that many partners of SCI persons experience satisfaction in their sexual relationships, affectional expressions and overall relationship parameters, even though many partners would prefer to engage in sexual activities more frequently. From the partners' perspective, trust, emotional closeness, mutual concerns and willingness to engage in a variety of sexual activities seem to be more important correlates for a positive sexual adjustment than the physiological aspects of sexuality.

\section{Acknowledgements}

This work was supported by grants from the Ministry of Health and Social Affairs-the Swedish Council for Social Research (No. 90-0180:1).

\section{References}

1 Trieschman RB (1988) Spinal cord injuries. Psychological, Social and Vocational Rehabilitation. 2nd ed. New York, Demos Publications.

2 Sjögren K, Egberg K (1983) The sexual experiences in younger males with complete spinal cord injury. Scand J Rehabil Med 9 (suppl): 189-194.

3 Teal JC, Athelsten GT (1975) Sexuality and spinal cord injury: some psychosocial considerations. Arch Phys Med Rehabil 56: 264-268.

4 Phelps G, Brown M, Chen J, Dunn M, Lloyd E, Stefanick ML et al (1983) Sexual experience and plasma testosterone levels in male veterans after spinal cord injury. Arch Phys Med Rehabil 64: 47-52.

5 Berkman AH (1975) Sexuality: a human condition. J Rehabil 41: 13-15.

6 De Vivo MJ, Fine PR (1985) Spinal cord injury: its short-term impact on marital status. Arch Phys Med Rehabil 66: 501-504.

7 Brown JS, Giesy B (1986) Marital status of persons with spinal cord injury. Soc Sci Med 23: 313-322.

8 De Vivo MJ, Jenkins KD, Go BK (1989) Outcomes of post-spinal cord injury marriages. Arch Phys Med Rehabil 70A: 50.

9 De Vivo MJ, Richards JS, Stover SL, Go BK (1991) Spinal cord injury rehabilitation adds life to years. West J Med 164: 602-606.

10 Crewe N, Krause JS (1988) Marital relationships and spinal cord injury. Arch Phys Med Rehabil 69: 435-438.

11 Deyoe FS Jr (1979) Marital and family relations following spinal cord injury. Arch Phys Med Rehabil 60: 542.

12 Jenik F, Kuhn W, Zach GA (1982) Social and vocational reintegration of paraplegic and tetraplegic patients in Switzerland. Paraplegia 20: 65-70.

13 Pinkerton AC, Griffin ML (1983) Rehabilitation outcomes in females with spinal cord injury: a follow-up study. Paraplegia 21: 166-175.

14 Urey JR, Henggeler SW (1987) Marital adjustment following spinal cord injury. Arch Phys Med Rehabil 68: $69-74$.

15 Urey JR, Viar V, Henggeler SW (1987) Prediction of marital adjustment among spinal cord injured persons. Rehabil Nurs 12: 26-30.

16 David A, Gurs S, Rozin R (1977-78) Survival in marriage in the paraplegic couple. A psychological study. Paraplegia 15: 198-201.

17 Kester BL, Rothblum ED, Lobato D, Milhous RL (1988) Spouse adjustment to spinal cord injury: long-term medical and psychosocial factors. Rehabil Counc Bull 32: 4-21.

18 Griffith ER, Tomko MA, Timms RJ (1973) Sexual function in spinal cord-injured patients: a review. Arch Phys Med Rehabil 54: 539-543.

19 Abrams KS (1982) The impact on marriages of adult-onset paraplegia Paraplegia 19: 253-259.

20 Stambrock M, Psych C, MacBeath S, Moore AD, Peters LC, Zubek E et al (1991) Social role functioning following spinal cord injury. Paraplegia 29: 318-323.

21 Willmuth ME (1978) Sexuality after spinal cord injury: a critical review. Clin Psychol Rev 7: 389-412.

22 Cronbach LJ (1951) Coefficient alpha and the internal structure of tests. Psychometrica 16: 297-334.

23 Nunnally JC (1978) Psychometric Theory. 2nd ed. McGraw-Hill Inc, New York.

24 Lundqvist C, Siösteen A, Lind B, Blomstrand C, Sullivan M A Shortened Measure of Function and Mood (submitted for publication). 
25 Bergner M, Bobbitt RA, Carter WB, Gilson BS (1981) The Sickness Impact Profile: development and final revision of health status measure. Med Care 19: 787.

26 Zigmond AS, Sainth RP (1983) The Hospital Anxiety and Depression scale. Acta Psychiatrica Scand 67: $361-370$.

27 Statistical Analysis Systems Institute (1990) Statistical Analysis System. SAS Institute, Cary, NC.

28 Bradley JW (1968) Distribution-free Statistical Tests. Prentice-Hall, London: 68-86.

29 Mantel N (1963) Chi-square test with one degree of freedom; extensions of the Mantel Haenszel procedure. J Am Stat Assoc 58: 690-700.

30 Boland JE (1983) The relationship between communication and marital satisfaction: a review. J Sex Marital Ther 13: 386-413.

31 Brehm SS (1984). Intimate Relationships. Sexuality, Sex and Satisfaction. Random House, New York.

32 Cubach WR, Comstock J (1990) Satisfaction with sexual communication in marriage: links to sexual satisfaction and dyadic adjustment. J Soc Pers Relationships 7: 179-186.

33 Masters WH, Johnson VE, Kolodny R (1986) Sex and Human Loving. Little Brown \& Co, Boston, MA.

34 Schenk J, Pfrang H, Rausche A (1983). Personality traits versus the quality of the marital relationship as the determinant of marital sexuality. Arch Sex Behav 12: 31-42.

35 Siösteen A, Lundqvist C, Blomstrand C, Sullivan L, Sullivan M (1990) Sexual ability, activity, attitudes and satisfaction as part of adjustment in spinal cord-injured subjects. Paraplegia 28:285-295.

36 Masters WH, Johnson VE (1986) Human Sexual Response. Little, Brown \& Co, Boston.

37 Kaplan HS (1974) New Sex Therapy. Active Treatment of Sexual Dysfunctions. Brunner/Mazel, New York.

38 Hatfield E, Greenberger E, Traupmann J (1982). Equity and sexual satisfaction in recently married couples. J Sex Res 18: 18-32.

39 Walster E, Walster HW, Traupman J (1978) Equity and premarital sex. J Personality 36: 82-92. 